\title{
PARAULES D'AGRAIIMENT PRONUNCIADES PER LA SENYORA MIREIA ESTEVA SALÓ
}

MiREIA EsteVA Saló

Escriptora

mireiaesteva@gmail.com

Magnífic Senyor Rector, padrins i altres doctors, públic que ens acompanya, bon dia a tothom.

En primer lloc, vull agrair la invitació feta per aquest rectorat de participar en aquest acte d'investidura com a doctor honoris causa, a títol pòstum, del meu pare, el Dr. Claudi Esteva Fabregat. Estic agraïda no tan sols pel que significa per a mi participar en un acte tan important i solemne dedicat al meu pare, cosa que m'emociona personalment, sinó també per la deferència i l'honor que signifiquen. Especialment, perquè sé que no és usual que els familiars hi intervinguin.

El meu pare, malauradament, no és aquí per manifestar els sentiments que l'embargaven quan va saber l'acord del Consell de Govern pel qual se'l nomenava doctor honoris causa. Vull que sàpiguen que va rebre

\footnotetext{
*Aquest text es correspon a les paraules d'agraïment pronunciades per la senyora Mireia Esteva Saló en la Investidura com a doctor honoris causa a títol pòstum del senyor Claudi Esteva Fabregat. Sessió acadèmica extraordinària del 10 de novembre de 2017.
} 
la notícia amb molta illusió i agraïment, i al mateix temps molt preocupat per si les seves condicions físiques li permetrien assistir-hi. Per poc temps, no va poder acomplir el seu desig, ja que la mort se'l va emportar el 4 de setembre passat. Demà hauria fet 99 anys.

Jo no sóc ni antropòloga ni acadèmica i, per tant no puc afegir res més des del punt de vista professional. Tan sols vull agrair en nom seu les paraules que aquí ja han dit els qui m'han precedit.

Els doctors Joan Prat Carós i Àngel Martínez Hernáez ens han illustrat, a través de les seves vivències, trets de la seva personalitat i la doctora Berta Alcañiz ha fet un recorregut per la seva biografia, fins el moment que va començar a dedicar-se a l'antropologia amb passió. Sense conèixer els fets que el van ajudar a madurar i els trets bàsics de la seva personalitat, no podríem entendre'n la trajectòria professional.

Quan hom fa un recorregut per la biografia i les fites professionals aconseguides, no pot fer-se una idea del grau de patiment i esforç que hi ha al darrere de cadascuna d'aquestes. Fill d'una família pobra, exiliat i sense professió, els inicis van ser molt llargs i molt difícils. No tan sols els inicis a Mèxic: també els inicis a Madrid, quan vam tornar a Espanya el 1956, quan jo tot just tenia set anys.

Com a exemple, els diré que el meu pare va començar la carrera quan la meva mare estava embarassada del tercer fill. Es guanyava molt malament la vida, venent estopa per als mecànics, i com que no tenia el batxillerat va haver de presentar-se als exàmens lliures per poder-se matricular posteriorment a l'Escola d'Antropologia. Va fer la carrera estudiant a les nits i venent estopa de dia, fins que va arribar a tal grau d'esgotament que un dia va caure desplomat al mig del carrer. També és illustratiu l'aprofitament que feia del paper. Qualsevol paper on hi hagués un espai sense utilitzar era aprofitable per fer el primer esborrany d'un article: els papers amb el compte de la botiga, les vores no impreses dels diaris o els sobres de la correspondència. Això ho ha continuat fent tota la vida.

Hi ha algunes característiques personals que em semblen rellevants:

Podem dir que era un lluitador que no es rendia mai, disposat a fer sacrificis per aconseguir el que es proposava. Qualitat que va afavorir una dedicació i entrega a la seva tasca professional, a la qual va dedicar la 
major part de la seva vida de forma exclusiva. També s'ha de destacar el gran sentit de responsabilitat, que feia que qualsevol tasca l'absorbís, de manera que mai repetia una classe que ja havia donat, perquè sempre hi afegia nova bibliografia, reflexions o matisos nous.

Una intelligència, sensibilitat i perspicàcia que el feien mirar més enllà de l'aparença de les coses, buscant-hi les causes o les explicacions més profundes o menys evidents. Descobriments i reflexions que compartia amb els fills o els alumnes, amb una vocació pedagògica que anava més enllà de les aules.

Era molt curiós i sempre es mantenia atent al que passava al seu entorn i a com evolucionava la professió. Això li va donar molta capacitat per aprendre i evolucionar al llarg de la vida, i la capacitat de viure molt intensament els canvis socials i sentir-se viu i implicat políticament.

Crec que aquestes qualitats són inseparables de l'acadèmia i haurien de ser qualitats necessàries per qualsevol persona que des de la universitat vulgui fer de la ciència també un servei a la societat.

Finalment, vull dir que el meu pare valorava molt el reconeixement que rebia de la tasca que feia, i malgrat que havia rebut premis molt importants com el Malinowski, el més important que es dona en el camp de l'antropologia, va rebre amb especial illusió i agraïment l'honor que la Universitat Rovira i Virgili havia decidit concedir-li.

Ens entristeix molt que ell ja no sigui aquí per manifestar-ho personalment, però valgui en nom d'ell l'agraïment que fem a la Universitat la seva família, materialitzat en el Magnífic Rector Josep Anton Ferré Vidal i tot l'equip que l'acompanya.

Moltes gràcies! 